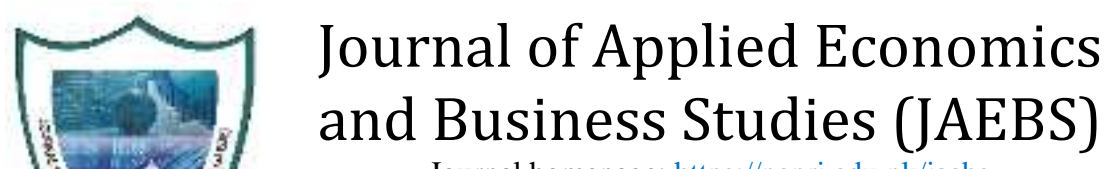

Journal homepage: https://pepri.edu.pk/jaebs

ISSN (Print): 2523-2614

ISSN (Online) 2663-693X

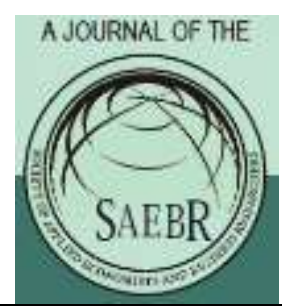

\title{
Digital Divide, Socio-Economic Outcomes and Subjective Well-Being in Higher Education Institutions of Pakistan
}

Atta ur Rahman ${ }^{* 1}$, Shandana ${ }^{2}$, Laila Taskeen Qazi ${ }^{3}$, and Adnan Khan ${ }^{4}$

${ }^{1}$ Institute of Management Sciences, Peshawar, Pakistan

${ }^{2}$ Institute of Management Sciences, Peshawar, Pakistan

${ }^{3}$ Institute of Management Sciences, Peshawar, Pakistan

${ }^{3}$ Institute of Management Sciences, Peshawar, Pakistan

\begin{abstract}
This research examines the relationship between internet usage, socioeconomic outcomes, and subjective well-being. Social outcomes are measured in the form of formal and informal networks and economic outcomes are measured through education, employment, and financial status. Subjective well-being is defined as assessment of one's own life satisfaction. The cross-sectional study is conducted through a survey. The data was collected through a self-designed questionnaire from 500 university graduates in different region of Pakistan. The Cox regression is used to investigate the relationship among the variables. In Cox regression the gender, education, major, subjective wellbeing (SWB), positive affect (PA), negative affect (NA) are significantly affecting the duration of internet usage. Internet usage increases with age, likewise internet usage is found more in women and married individuals than men and unmarried individuals. Economic outcomes are less for internet users than the non-users similarly social outcomes are lower for users than the nonusers. Similarly, internet usage is found to decrease with increase in the level of education. This shows how online activities affect the economic and social activities of the individuals and in turn affect their subjective well-being.
\end{abstract}

Keywords

Digital divide, Subjective wellbeing, SocioEconomics, Cox regression

JEL Classification Z1, Z13, A14

\section{Introduction}

Online communication has widely become common among the people as more attention is paid to the influences of online communication to people's life like information sharing, social adaption, interpersonal trust and subjective well-being. Subjective well-being is also gaining popularity in the recent years, and it has become a recognized subject matter in social sciences including economics. Due to new

\footnotetext{
*attaurrahman@imsciences.edu.pk
} 
emerging technologies, online communication such as instant messaging and social networking sites have obvious impact on subjective well-being of users. The skills and particular use of internet results in positive outcomes similarly inadequate use and skills can lead to limiting success.

Discussion about digital divide now means socioeconomic inequalities while accessing and using information and communication technologies and the use of such technologies namely internet, results in certain outcomes. Hence digital divide has left behind the discussion of having or not having access to internet and has come up with more factors like technical and social skills, motivation and awareness etc. Peoples online and offline activities are interrelated as it can benefit those who are using internet however internet abuse can create problems too. (Helsper, Deursen \& Eynon 2015)

Different types of internet usage skills results in useful outcomes to use information and communication technologies such as personal, social, cultural and economic wellbeing that are caused by online activities. According to (Helsper et al., 2015) these outcomes are useful in predicting the gratification of individuals which are the result of internet usage. Similarly, technology acceptance model explains the objective related to the internet usage and following activities related to internet outcomes according to needs and ease of use which results in happiness or well-being. Classification of economic and social capital is done as in terms of monetary assets and property for economic and for social in terms of relationship, social support and network. Similarly institutional (public formal information and services) and political participation through internet also results in outcomes and those online and offline activities have impact on each other.

The relevant theory can be found in the knowledge gap and usage gap hypotheses. Decades old theory i.e. knowledge gap hypothesis is about the traditional mass media in the digital divide concept that infuse information into the social system. The use of traditional mass media is simple as compared to internet, as internet usage requires technology as well as skills to use that technology (Bonfadelli, 2002). The difference in functionality is small in mass media e.g. print media, television, telephone as compared to internet use can create a usage gap. While the knowledge gap is the difference in getting information or knowledge from the mass media, the usage gap is about the society's ways of using internet differently (Van Dijk, 2013). The knowledge gap is not the outcome of a poorly operating media system but due to the social structure of the society, the information flow is not same, and the gap exists (Banfadelli, 2002). The usage gap as described by Van Dijk (2013) is the combination of societal tendencies and technological characteristics. Where societal tendencies are the socio-cultural and socio-economic differences according to income, employment, information and communication facilities and access. Technological characteristics involve the complex, expensive and multifunctional technologies regarding computer and internet which have different uses. 
The internet usage classifications are derived from internet activities. The usage is classified as Uses and Gratifications Approach, Technology Acceptance Model and Social Cognitive Theory. According to uses and gratifications approach internet is used for social and psychological purpose. It explains how users' needs affect their choices regarding entertainment, problem solving, social connection, information and diversion etc. (Cho, 2003). Technology Acceptance Model explains the intended behavior regarding the information system with two attitudes towards using a technology i.e. perceived usefulness and perceived ease of use; where the former explains using the system that improves the performance and the latter explains that using the system will be easier and free of effort (Davis, 1989). Social cognitive theory explains the psychosocial factors of society in the form of cognitive, behavioral, environmental events that affect each other. It explores the new behavior patterns of basic psychosocial factors such as getting knowledge of innovative behaviors, taking up these behaviors in practice and spreading through social networks (Bandura, 2001). Thus, it is related to the internet usage outcomes such as monetary outcomes, social outcomes, activity outcomes, novel outcomes, self-reactive and internal outcomes (LaRose et al., 2001).

In an information society, information functions in that society therefore people need social and cultural capital to use it in their social network. Cultural capital includes family traditions, education and other resources (Bucy and Newhagen, 2004). The social capital comprises networks, norms, trust, sociability etc. to pursue share objectives (Sabatini and Sarracino, 2014). However economic capital consists of family size, occupation, income and geographic location. The relation between these fields brings the concept of techno-capital which is beyond the physical access to computer technology and information in digital divide concept (Bucy and Newhagen, 2004).

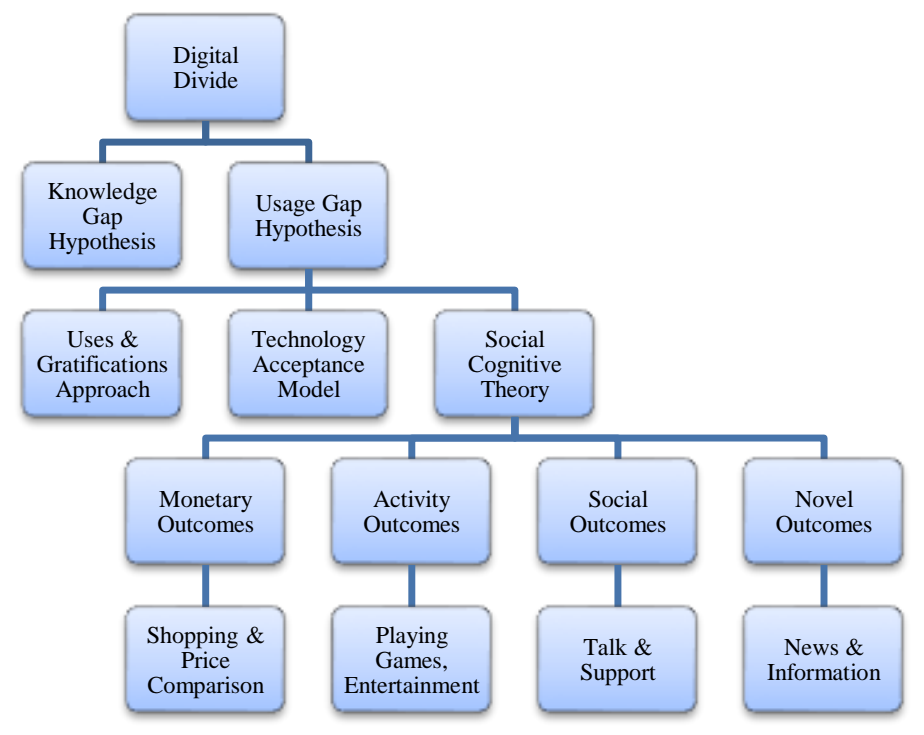

Figure: 1. Digital Divide 
Considering social capital in economics as trust and interaction is recognized for reduced transaction costs, facilitated investors and encouraged investment and innovation in human capital (Sabatini and Sarracino, 2014). Thus, key indicator of social capital is quality of social structure, networks, norms and trust; however, the measure of well-being is the quality of individuals' lives assessment by themselves with the most typical measure of life satisfaction (Helliwell, Huang and Wang, 2013).

\section{Literature Review}

Information and communication technologies (ICT) have the potential to offer immense advantages to users; it provides thorough information and opportunities for social and economic mobility. It can be the source of knowledge and expertise in education and health all across the world (Nanthikesan, 2000). The importance of information technology (IT) is still disputed in developing countries; it is viewed as a luxury for people living in poverty at the same time IT opens the door to economic opportunity, social and political mobilization, health care and education. For opening economic and other such opportunities, access to information through IT is necessary for the deprived sector (Hijab 2001). While discussing the inequalities regarding internet, only considering the demographic differences in access about who is online and who is not, is not as important as more people use internet now for communication and information purpose therefore the medium of use might be considered now (Hargittai 2010).

Subjective well-being has become a recognized topic of various social sciences including economics as it has become the agenda of political organizations, governments and international institutions. People's subjective well-being can be measured through responses to the questions about life satisfaction and happiness and it can help planning socio-economic policy (Praag 2001). People rely more on online networking for socializing and interacting with others and it turn out to be a new political and civic participation. Social capital i.e. face to face interactions and social trust are strongly associated with well-being. Subjective well-being is positively associated with face to face interactions however the use of social networking sites lowers the social trust which shows negative association with subjective well-being. The risk of fading social trust effects the life satisfaction i.e. subjective well-being. (Sabatini and Sarracino 2014). The use of information and communication technologies (ICTs) such as computers and mobile phones etc. has a significant impact on individual's wellbeing, yet so far very little is known about its impact in spite of its growing importance (Nie, Poza , Nimrod, 2017).

62 
In general, digital divide indicates the socio-economic inequality in access and use of ICTs, those who use it might get benefits from it however those who do not use it might be excluded from involvement in the contemporary society. Originally the digital divide was defined simply as the difference between having and not having the internet access, the difference was then accredited to difference in economic capital thus the financial resources get you connected. Helsper et al., 2015 measure tangible outcomes for internet usage as well as benefits from online networking. The study identifies scale for measuring internet outcomes that includes uses, skills and outcomes measures. The result of the study shows that different outcomes of internet usage have different levels of satisfaction for users. People achieving social outcomes do not necessarily be achieving the economic outcomes as well. Similarly, internet usage does not always help the user with outcome benefits. The study also reveals skills as important and different skill levels have different outcomes.

Selwyn (2010) argues that in contemporary higher education, digital divide is significantly gaining not losing; also the nature of existence of digital divide within the students of higher education needs to be understood more sophisticatedly. The use of information and communication technology (ICT) in higher education is a multifaceted concept that includes many activities through different platforms and means of connectivity. It requires skills that results in different outcomes. The use of ICT is a significant source of social inequality among university students. Authorities of higher education need to bridge the gap making the technological resources available to address the problem of the digital, Information and knowledge divide.

Hargittai (2010) analyzes data of young adults of almost same age and education level from different groups on internet uses and skills whether different uses of internet are caused by certain social factors or just a random distribution once the connectivity is achieved. The results show that variation exists in internet usage even when college students have the access/connectivity and students from lower socioeconomic status and female do not know much about web use regarding seeking information online. Students with more skills are involved in more activities online than those who do not have much knowledge.

Relationship between pattern of internet use and gratifications gained in the context of digital divide has been explored. Prominent difference in uses and gratifications are shown by the subgroups i.e. age and socioeconomic status. Young people with high socioeconomic status are likely to use internet more and for learning, enjoyment and motivation etc. (Cho et.al. 2003). 
Different factors of global digital divide have been taken in to account like economic, demographic, telecommunication infrastructure and others where a cross country econometric analysis has been done. The result shows that income is the most dominant factor in explaining the gap between the countries but there are other factors as well that at the same time are more effective e.g. telecommunication infrastructure. Similarly, policy variables like pricing the telecommunication access do not explain the internet gap that shows that it has been swamp by other factors like economic, demographic, and institutional. The paper shows importance of regulatory quality in technology usage (Chinn and Fairlie 2004).

MacLaren and Zappala (2002) analyze the influence of the usage and access of internet and computer within socioeconomic and demographic groups. The results show that parental education play important role in the use and access of computer and internet. Student from lower socioeconomic status use computer and internet mostly at school which shows that digital gap is closing at school levels. Robinson, Dimaggio and Hargittai (2003) observe that once the access is achieved, the difference in the usage can be different. People with more education use internet mostly for work, education, social and political engagements and very less for entertainment moreover the college educated is able to use new technology in a better way.

Hoffman and Novak (1998) and Rahman and Uddin (2009) examine that different educational and income background of different races affect the access and use of computer and web. Households with more/increasing level of income and education have access to computer and web than lower income households. Zillien and Hargittai (2009) investigates that socioeconomic status and context of use affect the online activities of users. Users with upper socioeconomic status use internet for capital enhancing than the opposite. It suggests that experience and improved equipment can decrease the digital inequalities.

Internet has become an important part of academia as a tool for education, communication and socializing as well, as it is not just confined to faculty research and communication but also used by students forgetting to know the society. Wang and Wang (2011) analyze that people who spend more time communicating online have higher subjective well-being hence show a positive relation between online communication and subjective well-being. Online communication has higher impact on boys as compared to the girls because of self-disclosure therefore it has more effect on subjective well-being of boys than for girls. 
Sabatini (2011) analyzes the relationship between e-shopping and happiness. Eshopping is changing the social and economic life of people and bringing growth to it. Ecommerce help consumer to have experiences than just to own goods and services and such experiences bring happiness and hence lead to subjective well-being. The results of the study indicate that e-commerce is positively and strongly related to well-being i.e. happiness. It also depicts that with increasing age, poor health and financial distress decrease happiness.

Economic outcomes are measured by indicators of education, employment, income and property that are related to illiteracy, unemployment and poverty e.g. finding a job online as access to job opportunity is wider, similarly online available information improves the performance, getting information online for educational purposes, availing discount offers online, buying and selling goods online. Social fields include networks that give access to knowledge and social and emotional support. Political and civic involvement through internet is also included in social field e.g. making opinions about politics, voting etc.

This research focus on the social and economic benefits/outcomes among the students of different disciplines resulting from different online activities also the relationship between the internet use and subjective well-being examined. Only social and economic fields have been selected as both are strongly interrelated. Economic outcomes are measured by income, education, employment and financial indicators that includes online job seeking, banking, buying and selling or for learning purposes. Social outcomes include the measures of different social networks (personal, political, formal) that give access to knowledge and support of others. Subjective well-being i.e. people's assessment of their own well-being as described by Sabatini and Sarracino (2014) is represented by the individual's life satisfaction.

The main objective of this research is to investigate that how socio-economic outcomes and subjective wellbeing affect duration of internet usage and this we test the hypothesis: $\mathrm{H}_{1}$ : Social outcomes and economic outcomes do not affect the duration of internet usage and that $\mathrm{H}_{2}$ : Subjective well-being does not have effect on duration of internet usage.

\section{Data Collection and Methods}

The participants of the study are 501 in numbers from different educational institutes in Pakistan with major in different disciplines. The sample size consisting of 501 participant was calculated with the help OpenEpi ${ }^{1}$ software. The three main factors

\footnotetext{
${ }^{1}$ http://www.openepi.com/Menu/OE_Menu.htm
} 
used to calculate the above-mentioned sample size include proportion of population using internet being 36\%, confidence level of $90 \%$ and $5 \%$ error. Data is collected online as well as offline i.e. questionnaires are distributed and filled by participants. Duration of internet usage is measured as internet use intensity in hours per day. It also includes the usage of social networking sites, blogs, games, emails and business websites.

The gender and marital status are dichotomous variables with male being 1 and female being 0 and 1 for married and 0 for unmarried. Education level is divided in four categories i.e. higher secondary school, bachelors (2 years), bachelors (4 years) and masters or above. Similarly current situation is measured in three categories i.e. studying, employed and unemployed. Educational programs are divided in three major disciplines i.e. medical, engineering and others including social and management sciences, art and humanities and agricultural studies. Subjective health is also measured by a 6 point scale 1 being very unhealthy to 6 being very healthy.

Satisfaction with life scale (SWL Scale; Diener et al., 1985) is used to measure the subjective well-being of the individuals. Subjective well-being is also measured by PANA Scale (positive affect and negative affect scale) by Watson et al., 1988. A 7-point likert scale is used in SWL scale to answer the questions with higher score showing more satisfaction with life. The PANA scale includes two components i.e. positive affect and negative affect that shows pleasant and unpleasant experiences of individuals. PANA scale includes 10 items; 5 positive and 5 negative.

The usage measurement has two categories i.e. social and economic. Internet use in social and economic field is measured by the subscales in outcomes measurement. Internet usage in economics fields includes education, property, employment and income. Similarly social fields includes personal, formal and political networks as used by Helpser's model of corresponding fields as it assumes the effect of digital usage on offline resources. Subscales are selected to measure the social and economic outcomes i.e. eight subscales for each variable. Variables of social and economic outcomes consists of sum scores based on individual items that is set on likert scale ranges from 1 being strongly agree to 7 being don't know.

Cox regression is used for time dependent variables and results are interpreted accordingly. The predicted variable is internet usage, however internet usage is computed as time i.e. in hours. The econometric model can be written as;

$$
h(t)=h_{0}(t) \exp \left(\beta_{1} x_{1}+\beta_{2} x_{2}+\cdots+\beta_{k} x_{k}\right) \ldots \ldots \ldots
$$

where $\mathrm{h}(\mathrm{t})$ is the duration of internet usage at time $\mathrm{t}, \mathrm{h}_{0}(\mathrm{t})$ is the baseline hazard and the $\mathrm{X}_{1}, \mathrm{X}_{2}, \mathrm{X}_{\mathrm{k}}$ are the $\mathrm{k}$ independent variables. 


\section{Data Analysis}

\subsection{Descriptive Analysis:}

Of the respondents, $62 \%$ were male and $38 \%$ were female with mean age 24 . Out of them, $40 \%$ were currently enrolled as undergraduate students, $18 \%$ post graduate students, $23 \%$ currently working, $8 \%$ reported as working part time and $10 \%$ unemployed. $37 \%$ were with medical as major, $34 \%$ engineering, the rest $29 \%$ with other disciplines such as $7 \%$ each in social sciences, management sciences/business studies, arts and humanities, 3\% agriculture and the rest 5\% from other disciplines. Furthermore, $85 \%$ are unmarried and $15 \%$ married. $98 \%$ have access to internet, where $89 \%$ use internet every day for different purposes.

Table 1: demographic profile of internet users/respondents

\begin{tabular}{|l|c|c|}
\hline Age & Frequency & Percent \\
\hline $16-20$ & 67 & 14.3 \\
\hline $21-25$ & 279 & 59.4 \\
\hline $26-30$ & 102 & 21.7 \\
\hline $31-35$ & 15 & 3.2 \\
\hline $36-40$ & 5 & 1.1 \\
\hline $41-45$ & 2 & .4 \\
\hline Gender & Frequency & Percent \\
\hline Female & 177 & 37.7 \\
\hline Male & 293 & 62.3 \\
\hline Total & 470 & 100.0 \\
\hline Education & Frequency & Percent \\
\hline Higher Secondary School & 81 & 17.2 \\
\hline Bachelors 2 years & 65 & 13.8 \\
\hline Bachelors 4 years & 201 & 42.8 \\
\hline Masters/Higher & 123 & 26.2 \\
\hline Current Status & Frequency & Percent \\
\hline Unemployed & 51 & 10.9 \\
\hline Employed & 150 & 31.9 \\
\hline Studying & 269 & 57.2 \\
\hline Major & Frequency & Percent \\
\hline Medical & 179 & 38.1 \\
\hline Engineering & 159 & 33.8 \\
\hline Others & 132 & 28.1 \\
\hline Marital Status & Frequency & 100.0 \\
\hline Unmarried & 400 & Percent \\
\hline Married & 70.1 \\
\hline Total & & 14.9 \\
\hline
\end{tabular}


Out of 470 respondents 201 are in their 4 years bachelors' program, 123 are doing masters or MS/MPhil/Ph.D., 65 are in their 2 years bachelors' program. 51 are unemployed, 150 are on job and 269 are getting education. 179 were studying medical, 159 engineering and 132 have other majors. 70 were married and 400 unmarried.

According to the calculation mean score of internet usage is 5.87 hours, mean score of economic and social outcomes is 4.04 and 3.85 respectively, and similarly SWB, PA and NA scale score 4.50, 0.57 and 0.45 respectively. The mean score of economic outcomes in terms of education is 4.11 that show agreement of the people that internet usage has economic outcomes in the field of education. Similarly, the fields of employment and income also show mean score of 4.27 and 4.11 which indicate the approval of the people about economic outcomes. Social outcomes in the form of formal and political networks also indicate that mostly people agree to the fact that internet usage has social outcomes.

Figure 1 explores access to online communication technology of the respondents. Most of the respondents have smart phone or tablet i.e. 403 out of 470 and 340 have laptop or desktop computers, 397 poses email accounts, 361 have accounts on social networking sites and 131 run a blog or a micro-blog.

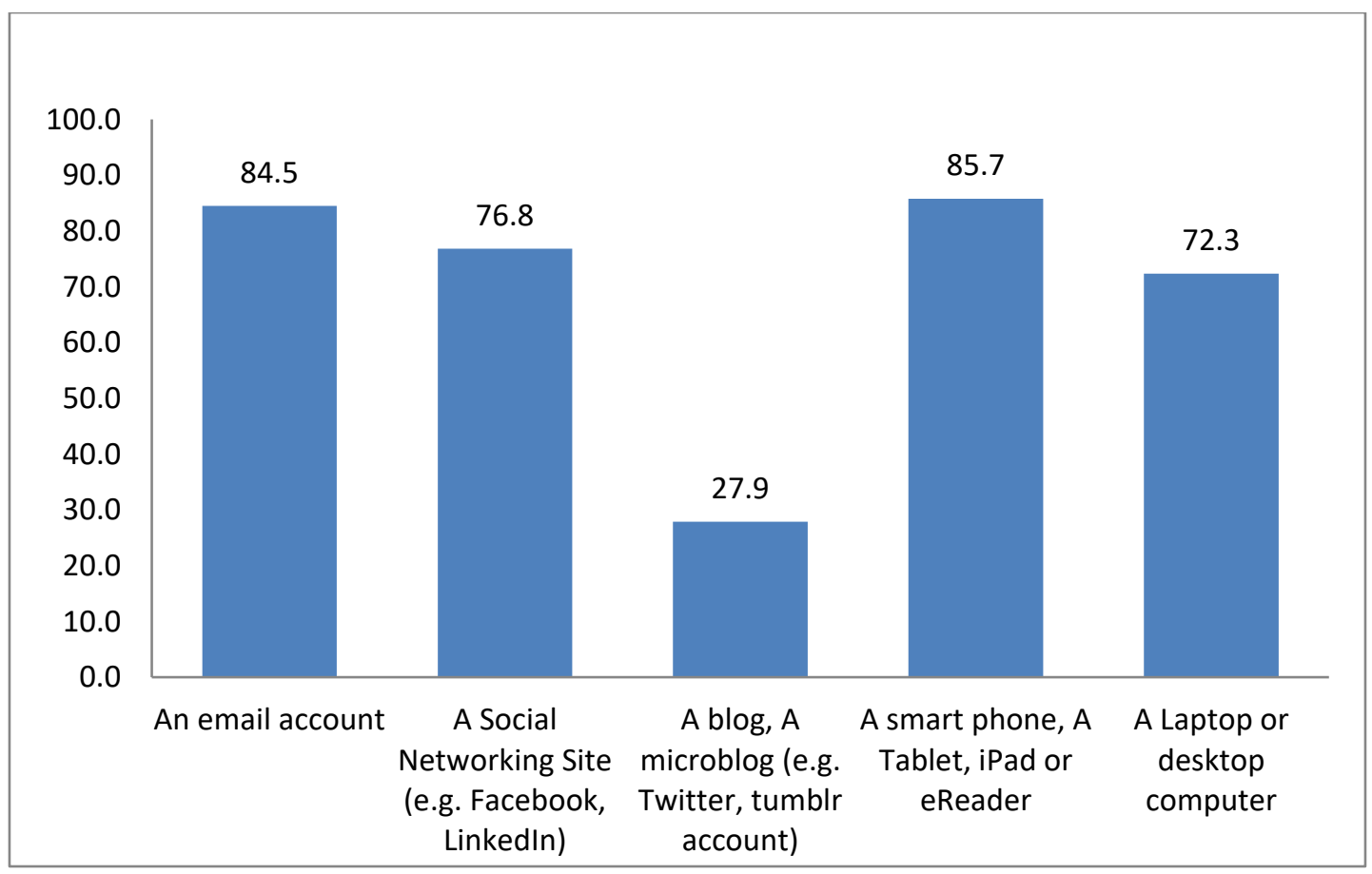

Figure 2: Internet Usage Intensity 
Figure 2 poses the daily activities of the respondents using internet. Most of the people spend their time using social networking sites (SNS) i.e. 310 numbers of respondent uses SNS daily out of 470. 257 use search engines for different purposes every day, 155 check their email daily, 70 respondents use internet for playing games every day, 43 respondents check business websites for online buying and selling purposes and only 32 use internets for blogging.

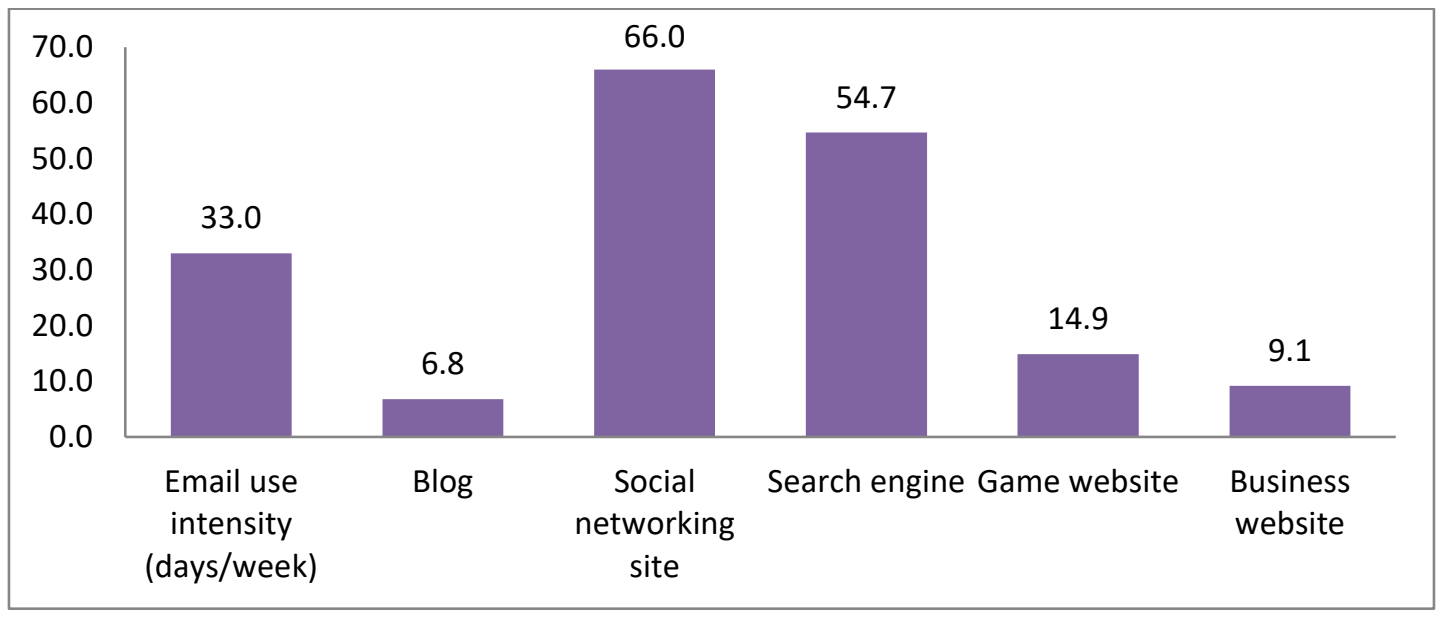

\subsection{Cox Regression}

Figure 3: Daily Online Activities

Cox regression is used with time dependent variable to investigate the relationship between time i.e. internet usage hours and predictor variables.

Table-3: Estimation results of Cox Regression for Internet usage time as dependent

\begin{tabular}{|l|c|c|c|c|c|c|}
\hline \multicolumn{7}{|c|}{ Variables in the Equation } \\
\hline Age & B & SE & Wald & df & Sig. & Exp(B) \\
\hline Gender & .010 & .027 & .143 & 1 & .705 & 1.010 \\
\hline Education & -.372 & .166 & 5.034 & 1 & .025 & .690 \\
\hline current status & -.169 & .094 & 3.209 & 1 & .073 & .845 \\
\hline Major & -.070 & .133 & .274 & 1 & .600 & .933 \\
\hline Marital Status & -.188 & .109 & 2.982 & 1 & .084 & .828 \\
\hline Subjective health & .273 & .234 & 1.360 & 1 & .244 & 1.314 \\
\hline Eco Outcomes & -.017 & .072 & .053 & 1 & .817 & .984 \\
\hline Social Outcomes & -.061 & .073 & .708 & 1 & .400 & .941 \\
\hline SWB & .207 & .085 & 1.717 & 1 & .190 & .895 \\
\hline PA & -.781 & .282 & 7.666 & 1 & .006 & .458 \\
\hline NA & -.515 & .255 & 4.087 & 1 & .043 & .598 \\
\hline
\end{tabular}


The above table 3 shows the results of Cox regression analysis. Internet usage is 0.01 times more in a person who is a year older than the other. Similarly, men use it 0.31 times less as compared to women. Married person use it $31 \%$ more than the unmarried one. A person using internet gets .059 times less economic outcomes than the person not using internet and social outcomes for internet user is $10.5 \%$ lower than the nonuser. The subjective well-being of the internet user is .23 times more than the one not using internet. Positive and negative analysis both shows $54 \%$ and $40 \%$ decrease respectively in the odds of using internet. P-value of the variables gender, Education, SWB, PA, NA significantly affecting the duration of internet usage.

\section{Discussion}

Fong (2009) results showed that there is significant relationship between information and communication technology (ICT) and gross national income per capita (GNI) of 91 developing countries is evaluated through regression analysis. This current study showed that there is no relationship between the two variables.

Sun, (2011) analyzes the effect of technology use on the performance of education. The findings of current study also suggest that education have significantly affecting the usage of internet.

Chou and Hsiao (2004) in their research investigate the internet addiction of college students and the patterns they follow while using internet and gratification and communication pleasure by using internet. The results show self-reported pleasure being the strongest predictor of internet usage and internet "Addicts" spend three times more hours on internet than the "non-addicts" specifically on web, email, games and online communication and socializing applications such as BBS which is used in Taiwanese institutes. Internet users who use internet for more hours are satisfied and happier than the one who use internet less. However, this negatively affects the daily routine and studies of users but positively affect the relationship with friends and family. The result here in this research suggests that search engines and social networking sites are the tools, respondents spend most of their time on while using internet. However, the social networks i.e. relationship with friends and family members through online communication show negative association with internet usage. Results of cox regression show that economic outcomes are less for internet users than the people not using it, similarly social outcomes are lower for users than the nonusers. This shows how online activities affect the economic and social activities of the individuals and in turn affecting 70 
their subjective well-being. Both the models in the research express positive relationship of subjective well-being with internet usage and higher subjective well-being show higher satisfaction with life.

Similarly (Dennis, et al., 2015) examine the relationship between social exclusion causing shopping and its effects on wellbeing and happiness. The results show that people who consider themselves socially excluded spend more time shopping online (through smart phone and computer) and offline (physically). The results indicate that however social exclusion negatively affects the wellbeing and happiness; people spent time shopping to overcome that feeling. Research suggests that people use internet in order to lessen their depression.

The results of the (Robinson, Dimaggio and Hargittai, 2003) results show that college or higher educated people use internet more than students of lower education level (high school) in the form of education and later on job finding in the long-term personal usage in the short term by communicating with family relations and friends through internet. Wang and Wang (2011) use linear regression to find out the relationship online communication and subjective well-being of users. The results show positive association between subjective wellbeing and online communication also boys benefit more than girls in terms of gaining wellbeing from internet usage.

According to usage and gratification theory people use internet for different purposes such as information gaining and socializing etc. through different applications and tools that results in pleasure and satisfaction of the users. Nie, et al., (2017) analyze the relationship between internet usage and different measures of subjective wellbeing. The results of the study show negative association of internet usage with life satisfaction and happiness and close association with depression. The results are like this research where internet usage is positively related to life satisfaction and negatively associated with happiness and depression. Cho et.al. (2003) explains the relationship between internet usage and pleasure gained from it and the finding indicates that young people with higher socio-economic status use internet to gain pleasure and feel satisfied through communication and learning.

The cox regression shows that internet usage increase with age, similarly women and married people use internet more than men and unmarried people. Economic and social outcomes show negative relationship with internet usage in other words internet usage has less economic and social outcomes. Binary logistic regression shows same results for age, gender, marital status, discipline, for social and economic outcomes and 
for subjective well-being. With increase in age, internet usage also increases, likewise internet usage is found more in women and married individuals than men and unmarried individuals. Similarly employed people use it more than the unemployed one.

The relationship between socio-demographic variables and internet use and types of internet usage is analyzed by Deursen and Djik (2013) through linear regression

analysis. The results show that disabled and less educated people spend more time using internet than the people who are more educated. Age, gender and education prove to be the strong predictors of internet usage. However the results of Porter and Donthu (2006) paper are opposite the above mentioned results by Deursen and Djik (2013). It shows that highly educated, wealthy and young people use internet more than the less educated, poor and older people. Findings of the research are considered useful in terms of personal, social and economic fields as it helps in policy making and benefits the society.

Hargittai (2010) investigates the relationship between socio-economic status and internet users' skills and types of internet usage. The results of the study show that not everyone has the internet knowledge therefore usage is different as white people (male gender) with educated parents have better internet usage skills than the opposite ones. Similarly, the research proves socio-economic status as strong predictor of internet usage skills. MacLaren and Zappala (2002) also conclude that internet access to the children of lower socio-economic status is strongly connected to the education of parents also internet access at home is beneficial for the performance of children in education. The researcher suggests that internet access to people with lower socioeconomic status need to be preferred by policy makers.

\section{Conclusion}

This research investigates the impact of age, gender, education, employment and marital status, its relation to social and economic outcome and subjective well-being on internet usage. Age, marital status and subjective well-being show positive affect on internet usage however gender, economic and social outcomes have negative affect on internet usage. Different use of internet in different age is likely to be a temporary difference as the young generation will grow old and also the older people are getting more involved in online activities for socializing etc. However some part of inequality will remain in age and gender because of social and cultural preferences of the society. 
Different use of internet associated with the education has long-term effects as it is related to the information and knowledge of the society.

The analysis of the data revealed the classification of internet use that people mostly prefer while using and spending time on, are social networking sites and search engines. Uses and Gratification theory is endorsed by the classification of internet usage that shows the motives of the users. As Chou, Condron \& Belland (2005) says that internet is changing the society's way of living and although the use of internet can be similar, but the outcomes and effects are dissimilar that ultimately depends on the nature of use. Internet usage improves the skills, abilities and potentiality of the users but at the same time it also results in inappropriate use hence leading to both positive and negative outcomes. Findings of the research suggest that internet usage leads to the result of negative social outcomes. It suggests that users who get economic outcomes of internet do not necessarily get the same social outcomes as well. Similarly benefits from online activities on internet do not necessarily mean that offline activities i.e. activities other than digital involvement, are not beneficial and important in our life. Economic outcomes are more important for policy makers than social (formal and informal networks) outcomes as they are associated with education and employment.

The relationship between internet use and subjective well-being is positive that shows positive relationship of internet with life satisfaction, it also shows higher level of depression and negative association with happiness through positive affect and negative affect analysis (PANA). Since internet users are new and amateur, it is possible that the use will change after some time as internet will become more dominant and users will become more experienced. Future research can include personal and cultural fields to investigate the outcomes of internet usage. Race, location and access to internet may also affect the internet usage therefore difference of use between the literate and illiterate, urban and rural differences showing geographical inequalities can be investigated. 


\section{References}

Bandura, A. (2001). Social cognitive theory: An agentic perspective. Annual review of psychology, 52(1), 1-26.

Bonfadelli, H. (2002). The Internet and knowledge gaps: A theoretical and empirical investigation. European Journal of communication, 17(1), 65-84.

Bucy, E. P., \& Newhagen, J. E. (Eds.). (2004). Media access: Social and psychological dimensions of new technology use. Psychology Press.

Chinn, M. D. \& Fairlie, R. W. (2004). The Determinants of the Global Digital Divide: A cross-country analysis of computer and internet penetration. Center for Global, International and Regional Studies UC Santa Cruz, eScholarship.

Cho, J., De Zúñiga, H. G., Rojas, H. \& Shah, D. V. (2003). Beyond Access: The Digital Divide and Internet Uses and Gratifications. IT \& Society, 1 (4), 46-72.

Chou, C. \& Hsiao, M. C. (2000). Internet addiction, usage, gratification, and pleasure experience: the Taiwan college students' case. Elsevier Science Ltd., Computers \& Education, 35, 65-80.

Chou, C., Condron, L. \& Belland, J. C. (2005). A Review of the Research on Internet Addiction. Educational Psychology Review, 17 (4), 363-388.

Dennis, C., Alamanos, E., Papagiannidis, S., \& Bourlakis, M. (2016). Does social exclusion influence multiple channel use? The interconnections with community, happiness, and well-being. Journal of Business Research, 69(3), 1061-1070.

Davis, F. D. (1989). Perceived usefulness, perceived ease of use, and user acceptance of information technology. MIS quarterly, 319-340.

Diener, E. D., Emmons, R. A., Larsen, R. J., \& Griffin, S. (1985). The satisfaction with life scale. Journal of personality assessment, 49(1), 71-75.

Fong, M. W. L. (2009). Digital Divide: The Case of Developing Countries, Informing Science and Information Technology, 6, 471-478.

Hargittai, H. (2010). Digital Na(t)ives? Variation in Internet Skills and Uses among Members of the "Net Generation". Sociological Inquiry, 80 (1), 92-113.

Helliwell, J. F., Huang, H., \& Wang, S. (2014). Social capital and well-being in times of crisis. Journal of Happiness Studies, 15(1), 145-162. 
Helsper, E. J., van Deursen, A. J. A. M. \& Eynon, R. (2015). Tangible Outcomes of Internet Use, From Digital Skills to Tangible Outcomes project report of Oxford Internet Institute.

Hijab, N. (2001). People's Initiatives to Use IT for Development. UNDP.

Hoffman, D. L., \& Novak, T. P. (1998). Bridging the Digital Divide: The Impact of Race on Computer Access and Internet Use.

LaRose, R., Lin, C. A. \& Eastin, M. S. (2003). Unregulated Internet Usage: Addiction, Habit, or Deficient Self-Regulation? Lawrence Erlbaum Associates, MEDIA PSYCHOLOGY, 5, 225-253.

MacLaren, J. \& Zappala, G. (2002). The Digital Divide among Financially Disadvantaged Families in Australia. First Monday, 7 (11), 1-22.

Nanthikesan, S. (2000). Trends in digital divide. Harvard Center for Population and Development Studies, Cambridge, MA.

Nie, P., Sousa-Poza, A., \& Nimrod, G. (2017). Internet use and subjective wellbeing in China. Social Indicators Research, 132(1), 489-516.

Payton, F. C. (2003). Rethinking the Digital Divide. COMMUNICATIONS OF THE ACM, 46 (6), 89-92.

Porter, C. E. \& Donthu, N. (2006). Using The Technology Acceptance Model to Explain How Attitudes Determine Internet Usage: The Role Of Perceived Access Barriers and Demographics. Elsevier, Journal of Business Research, 59, 999-1007.

Robinson, J. P., DiMaggio, P. \& Hargittai, E. (2003). New Social Survey Perspectives on the Digital Divide. IT \& Society, 1 (5), 1-22.

Rahman, A. U., \& Uddin, S. (2009). Statistical Analysis of Different Socio Economic Factors Affecting Education of N.W.F.P (Pakistan). Journal of applied quantitative methods, 4(1), 88-94.

Sabatini, F. (2011). Can a click buy a little happiness? The impact of businessto-consumer e-commerce on subjective well-being. MPRA Munich Personal RePEc Archive, 32393, posted 24. July 2011 15-40.

Sabatini, F., \& Sarracino, F. (2014). Will Facebook save or destroy social capital? An empirical investigation into the effect of online interactions on trust and networks. 
Selwyn, N. (2010). Degrees of Digital Division: Reconsidering Digital Inequalities and Contemporary Higher Education. RUSC. Universities and Knowledge Society Journal, 7 (1), 33-42.

Sun, J. C. Y., \& Metros, S. E. (2011). The Digital Divide and Its Impact on Academic Performance. Online Submission.

Van Dijk, T. A. (2013). News as discourse. Routledge.

Van Deursen, A. J. A. M. \& Van Djik, J. A. G. M. (2014). The Digital Divide Shifts to Differences in Usage. SAGE Publications, 16 (3), 507-526.

Van Praag, C. M., \& Cramer, J. S. (2001). The roots of entrepreneurship and labour demand: Individual ability and low risk aversion. Economica, 68(269), 45-62.

Wang, J. \& Wang, H. (2011). The Predictive Effects of Online Communication on Well-Being among Chinese Adolescents. Scientific Research, Psychology, 2 (4), 359-362.

Watson, D., Clark, L. A., \& Tellegen, A. (1988). Positive and negative affect schedule (PANAS). Journal of Personality and Social Psychology, 54(6), 1063-1070.

Young, K. S. (2004). Internet Addiction, A New Clinical Phenomenon and Its Consequences. SAGE Publications, 48 (4), 402-415.

Zillien, N., \& Hargittai, E. (2009). Digital distinction: Status-specific types of internet usage. Social Science Quarterly, 90(2), 274-291. 